\title{
Watch and learn? A systematic review comparing oral health educational videos with written patient information aimed at parents/carers or children
}

\author{
Fionnuala Loy, ${ }^{\star 1}$ Ben Underwood ${ }^{2}$ and Claire Stevens ${ }^{3}$
}

\section{Key points}

Highlights the need for innovative ways to deliver oral health education for children during the COVID-19 pandemic.
Critically appraises currently available studies comparing video information with conventional written patient information aimed at children or parents/carers.
Provides suggestions for future research into video education.

\begin{abstract}
Introduction Childhood caries remains a major UK health issue. The COVID-19 pandemic has necessitated rapid introduction of innovative practice to minimise footfall into dental clinics. Video-based oral health education could help promote oral health advice remotely and has been included in national guidance. This systematic review evaluates the impact of video education versus written patient leaflets on knowledge and oral health behaviours in parents/carers or children.
\end{abstract}

Method PubMed and Medline were searched. In total, 47 articles were identified and relevance assessed by examining titles and abstracts. Seven full-text articles were assessed and reference lists manually screened for additional publications. Three studies met the inclusion criteria.

Results Only one study assessed participant knowledge gain and found no statistical significance between scores at baseline and after video, leaflet or hygienist-led education. For oral health behaviour change, one study demonstrated no significant difference in plaque score improvements between video and leaflet groups. The other showed significant improvements in plaque and bleeding scores for both leaflet and video groups compared to the control.

Conclusion This review identified too few studies with heterogeneity to make conclusions on the impact of written versus video oral health education. A standardised outcome measurement tool is needed to evaluate the impact of current educational videos on oral health behaviour and knowledge. There is potential for video to educate the masses as we navigate through this pandemic.

\section{Introduction}

Benjamin Franklin stated that 'an ounce of prevention is worth a pound of cure.' Dental caries is an entirely preventable yet highly prevalent disease, that negatively impacts patients, their families and our National Health Service. The Public Health England national oral health survey for five-year-olds in 2019

'Dental Core Trainee 2, North West, Maxillofacial Surgery Department, Royal Preston Hospital, Preston, PR2 9HT, UK

${ }^{2}$ General Dental Practitioner, Founder and CEO of Brush DJ Ltd, UK; ${ }^{3}$ Consultant in Paediatric Dentistry, Manchester University NHS Foundation Trust, Manchester, M15 6FH, UK.

${ }^{\star}$ Correspondence to: Fionnuala Loy

Email address: floy@tcd.ie

Refereed Paper.

Accepted 17 February 2021

https://doi.org/10.1038/s41415-021-3616-5 showed that $23.4 \%$ of children in the study had experience of dental decay. ${ }^{1}$ This result is very similar to the 2017 findings, which showed a $23.3 \%$ prevalence of dental decay in five-yearolds. ${ }^{2}$ This indicates that recently, insufficient progress has been made towards tackling this unacceptable level of disease. Furthermore, childhood caries disproportionately affects children in deprived areas (34.3\%) than in less deprived areas of England (13.7\%). ${ }^{1}$ Dental disease has been shown to have a negative impact on family life. ${ }^{3}$ Moreover, children with carious primary teeth are more at risk of sepsis and caries in future. ${ }^{4,5}$ Dental caries and tooth extraction in 5-9-year-olds remains the number one reason for hospital admissions in England. ${ }^{6}$ In 2015-2016, the NHS spent $£ 50.5$ million on tooth extractions for patients aged 0-19 years and the majority were for tooth decay. For children aged four years and under, the cost of tooth extractions was $£ 7.8$ million. ${ }^{7}$

In 2003, the World Health Organisation suggested that the focus of oral health education should be on promoting conditions that allow people to take control, improve their health and reduce the risk of oral disease. ${ }^{8}$ Systematic reviews to evaluate the effectiveness of oral health education methods have shown some positive results for short-term knowledge acquisition and reduction in plaque accumulation..$^{9,10,11}$ However, due to the absence of homogeneity among articles, owing to the lack of uniformity and strict guidelines existing to conduct a randomised control trial (RCT) with oral health education as an intervention, further efforts are required to systematically synthesise information in this area. 
The various methods of delivering oral health care education include written pamphlets, face-to-face counselling, mobile and webbased applications and videos. Medical health interventions utilising video or DVDs have proven to be convenient, accessible and potentially cost-effective inventions in motivating positive changes in patient behaviour..$^{12}$ In addition, video education can increase uptake of those with low literacy skills and provide a standardised health message and delivery. ${ }^{13}$

The first systematic review to examine the effectiveness of videos in promoting behaviour health changes concluded that videos were variably effective in promoting health changes but were dependant on the target behaviours to be influenced. The review demonstrated that video modelling and gain-framed messages may be more effective in facilitating learning of new behaviours. ${ }^{12}$ However, none of the studies included in this systematic review were related to oral health education specifically. A recent prospective cohort pilot study found a statistically significant improvement in overall oral hygiene knowledge in children in Year 3 but not in Year 2 at two weeks, after watching a peerled oral hygiene education video. ${ }^{14}$ The authors concluded that a RCT is needed to compare video education against a gold standard.

The COVID-19 pandemic resulted in the release of new guidelines and a dramatic suspension of dental services, resulting in more challenging access to primary and secondary care services. ${ }^{15,16}$ Oral health prevention advice is more important now than ever. The British Society of Paediatric Dentistry (BSPD) have adapted to the pandemic and released age-targeted oral health promotion videos, available on YouTube. ${ }^{17}$ It has been recommended for dentists to encourage patients to access these videos as part of caries prevention by the Office of the Chief Dental Officer in dental national guidance. ${ }^{18}$

Patient leaflets are a long-established form of patient education. A 2016 review of general dental practice teams on promoting oral health found strong evidence for leaflets being effective at increasing patient knowledge but no evidence to support that leaflets affect health outcomes. ${ }^{19}$ Two RCTs studied information leaflets aimed specifically at parents and found improvements in short-term parental knowledge of tooth avulsion and how to manage it. ${ }^{20,21}$ However, although results look promising, further statistical analysis is needed to confirm improvements are statistically significant.

During this uncertain time of reduced face-to-face dental care, social distancing and minimising contact, video education seems an attractive and accessible method of conveying oral health education to the masses. However, it is important to evaluate the evidence for video education against other, well-established oral health education methods, to guide future public oral health education decisions.

\section{Materials and methods}

A search was conducted using Medline and PubMed databases from its inception to 15 July 2020. This systematic review was completed in line with the Preferred Reporting Items for Systematic Reviews and Meta-Analyses (PRISMA) guidelines. ${ }^{22}$

The primary objective of this review was to assess the impact of video-based patient education as a sole intervention on the knowledge and/or oral health behaviour of children or parents/carers of children receiving oral health education, compared to conventional written patient information. For the purpose of this review, the term 'child' or 'children' was defined as anyone between 0-16 years of age. ${ }^{23}$ A secondary objective was to describe currently reported styles of video-based patient information for oral health promotion.

To meet the inclusions criteria, articles had to be peer-reviewed, published studies of primary research. Studies were included in this review if they compared patient education videos as an intervention with traditional, written patient information for children or parents/carers of children, receiving oral health education. The endpoints had to be focused on patient knowledge and/or oral health behaviours. Publications that did not fulfil the inclusion criteria and any duplicate papers were excluded from this systematic review.

\section{Inclusion criteria}

- Primary research relating to the impact on knowledge gained by parents/carers or children and/or oral health behaviour of children receiving oral health advice comparing educational videos with written patient information

- English language only

- Published literature only.

\section{Exclusion criteria}

- Primary research relating to knowledge gained and/or impact on oral health behaviours using any other forms of educational material other than educational videos or written information
- Not English language

- Unpublished literature.

See Table 1 for full search strategy. The initial screening was conducted by two independent authors (FL and BU). All article titles and abstracts were read and those that did not meet the inclusion criteria or found to be duplicates were excluded. Studies which met inclusion criteria from the initial screening process were put forward and full text screening was conducted to yield the final articles to be included for data extraction. Reference lists from the full-text screening articles were assessed and any relevant articles were also selected for full text screening. Any discrepancies in study selection were discussed to try and reach a consensus. If this was not possible, a third author (CS) was contacted for review to decide whether to include or exclude the study. After completion of this screening process, the data from the included articles were extracted independently by the two authors.

\section{Results}

The search strategy yielded 47 results. After screening, three studies were included for data extraction (Table 2). Study selection is shown in the PRISMA flow diagram (Fig. 1). Of the included studies in this systematic review, two were randomised control studies. ${ }^{24,25}$ The remaining study was an uncontrolled randomised trial. ${ }^{26}$ In total, 581 participants were included in this systematic review after consideration of participant dropouts (range 65-388). Two of the three studies included were from Iran and were multicentre. ${ }^{24,25}$ The other study was conducted in England as a singlecentre study. ${ }^{26}$

\section{Effect of studies on participant knowledge}

Only one study assessed oral health knowledge gained by the participants after video education. A. Lees and W. P. Rock administered a pre- and post-study questionnaire which tested knowledge through open questions regarding diet and oral health care, focusing on hygiene for fixed appliances. The average oral health knowledge questionnaire score before patient education was $38 \%$. Post-study questionnaire results were not statistically significant when compared to baseline. There was an improvement in oral health knowledge questionnaire score of $17.2 \%$ and $22.6 \%$ post-video education and hygienist-led education, respectively and a 
decrease of $7.2 \%$ post-written education was reported after eight weeks. ${ }^{26}$

\section{Effect of studies on oral health behaviours}

All three studies assessed changes to oral health behaviours. However, only two of the three studies showed statistically significant improvements, specifically to plaque and/or gingival bleeding scores after patient video education or written patient information. ${ }^{24,25}$

In the study by Ramezaninia et al., the Plaque Index (PI) by Silness and Löe was assessed at baseline, 24 hours, 4 weeks and 8 weeks post-education, by two non-blinded, trained, senior dental students. A score of $0.1 \leq \mathrm{PI} \leq 1$ was considered a good status of oral and dental hygiene. At baseline line, all groups had a PI score $<1$ except for the pamphlet group which scored PI $=1.02 \pm 0.39$. There were significant improvements in PI scores at eight weeks when compared to baseline results for students receiving lecture $(0.14 \pm 0.12)$, video $(0.18 \pm 0.11)$ and pamphlet $(0.24 \pm 0.20)$ education $(\mathrm{P}<0.001)$. The control group, which received no oral health education, showed worsening PI scores at eight weeks ( $1.04 \pm 0.40$, $\mathrm{P}=0.01$ ). There were no statistically significant differences in improvements between the groups $(\mathrm{P}<0.001)$. In the pamphlet group, boys had greater, statistically significant improvements in PI scores at eight weeks than girls (boys $=0.27 \pm 0.27$ and girls $=0.21 \pm 0.11$, $\mathrm{P}=0.03)$. There were no other statistically significant differences in PI scores between genders in any other group. ${ }^{25}$

In the study by Yazdani et al., a modified Silness and Löe PI and the bleeding criterion from the Community Periodontal Index was used on six index teeth by blinded, trained examiners. At baseline, mean sum scores for dental plaque were 8.8 (SD 2.6) (boys $=9.2$, girls $=8.5)$ and for gingival bleeding 3.9 (SD 1.8) (boys $=4.2$, girls $=3.7$ ). All students had dental plaque and 93\% of students had gingival bleeding on at least one index tooth, with no differences between control and intervention groups. ${ }^{24}$

Improvements in the leaflet and video groups at 12 weeks for mean sum scores of dental plaque were statistically significant compared to the control (at baseline, leaflet group $=8.8$, videotape group $=8.4$ and control group $=9.1$ [P >0.05] and at 12 weeks, 4.5, 5.5 and 8.9, respectively $[\mathrm{P}<0.05])$. The mean reduction in dental plaque at 12 weeks in the video group when compared to the control group was not statastically significant for girls (1.5, SD 2.9,
Table 1 Search strategy

\begin{tabular}{|c|c|c|c|}
\hline Number & Database & Search term & Results \\
\hline 1 & PubMed & (health education).ti, ab & 705,727 \\
\hline 2 & PubMed & (health promotion).ti,ab & 146,709 \\
\hline 3 & PubMed & (patient education).ti,ab & 100,788 \\
\hline 4 & PubMed & (health communication).ti, ab & 152,246 \\
\hline 5 & PubMed & (information dissemination).ti,ab & 25,665 \\
\hline 6 & PubMed & (persuasive communication).ti, ab & 4,070 \\
\hline 7 & PubMed & $\begin{array}{l}\text { ((health OR patient*) ADJ3 (promotion OR education OR instruction* } \\
\text { OR advice OR program OR outreach OR communicate* OR campaign* } \\
\text { OR initiative* OR knowledge)).ti,ab }\end{array}$ & 64,721 \\
\hline 8 & PubMed & (oral health).ti,ab & 173,956 \\
\hline 9 & PubMed & (dental health).ti,ab & 238,052 \\
\hline 10 & PubMed & (teeth).ti,ab & 239,451 \\
\hline 11 & PubMed & $($ video*).ti, ab & 143,648 \\
\hline 12 & PubMed & (educational video).ti,ab & 576 \\
\hline 13 & PubMed & $($ film*).ti,ab & 180,508 \\
\hline 14 & PubMed & (leaflet* OR pamphlet* OR booklet*).ti,ab & 29,972 \\
\hline 15 & PubMed & ((print OR printed OR paper) ADJ (material* OR matter OR media)).ti,ab & 5,670 \\
\hline 16 & PubMed & (1 OR 2 OR 3 OR 4 OR 5 OR 6 OR 7) & 924,762 \\
\hline 17 & PubMed & (8 OR 9 OR 10) & 443,045 \\
\hline 18 & PubMed & $(11$ OR 12 OR 13) & 321,709 \\
\hline 19 & PubMed & $(14$ OR 15) & 35,609 \\
\hline 20 & PubMed & (16 AND 17 AND 18 AND 19) & 33 \\
\hline 21 & Medline & (health education).ti, ab & 164,432 \\
\hline 22 & Medline & (health promotion).ti,ab & 43,078 \\
\hline 23 & Medline & (patient education).ti,ab & 72,641 \\
\hline 24 & Medline & (health communication).ti, ab & 49,957 \\
\hline 25 & Medline & (information dissemination).ti,ab & 8,040 \\
\hline 26 & Medline & (persuasive communication).ti,ab & 348 \\
\hline 27 & Medline & $\begin{array}{l}\text { ((health OR patient*) ADJ3 (promotion OR education OR instruction* } \\
\text { OR advice OR program OR outreach OR communicate* OR campaign* } \\
\text { OR initiative* OR knowledge)).ti,ab }\end{array}$ & 235,663 \\
\hline 28 & Medline & (21 OR 22 OR 23 OR 24 OR 25 OR 26 OR 27) & 401,852 \\
\hline 29 & Medline & (oral health).ti,ab & 60,766 \\
\hline 30 & Medline & (dental health).ti,ab & 35,324 \\
\hline 31 & Medline & (teeth).ti,ab & 108,129 \\
\hline 32 & Medline & (29 OR 30 OR 31) & 176,063 \\
\hline 33 & Medline & $($ video*).ti, ab & 108,420 \\
\hline 34 & Medline & (educational video).ti,ab & 2,851 \\
\hline 35 & Medline & $(f i l m *) . t i, a b$ & 174,856 \\
\hline 36 & Medline & (33 OR 34 OR 35) & 281,225 \\
\hline 37 & Medline & (leaflet* OR pamphlet* OR booklet*).ti,ab & 27,163 \\
\hline 38 & Medline & ((print OR printed OR paper) ADJ (material* OR matter OR media)).ti,ab & 2,178 \\
\hline 39 & Medline & (37 OR 38) & 29,254 \\
\hline 40 & Medline & (28 AND 32 AND 36 AND 39) & 14 \\
\hline
\end{tabular}




\begin{tabular}{|c|c|c|c|c|c|c|c|c|c|}
\hline $\begin{array}{l}\text { Study } \\
\text { no. }\end{array}$ & $\begin{array}{l}\text { Author } \\
\text { (year) }\end{array}$ & $\begin{array}{l}\text { Study design, } \\
\text { country, } \\
\text { single- or } \\
\text { multi-centre }\end{array}$ & $\begin{array}{l}\mathrm{N} \\
\text { Intervention } \\
\text { group(s) }\end{array}$ & $\begin{array}{l}\mathrm{N} \\
\text { Control } \\
\text { group }\end{array}$ & Intervention & $\begin{array}{l}\text { Age of } \\
\text { participants }\end{array}$ & $\begin{array}{l}\text { Outcome(s) } \\
\text { assessed }\end{array}$ & $\begin{array}{l}\text { Improvement } \\
\text { post-intervention }\end{array}$ & $\begin{array}{l}P \\
\text { values }\end{array}$ \\
\hline \multirow[t]{2}{*}{1} & \multirow{2}{*}{$\begin{array}{l}\text { J. Ramezaninia } \\
\text { etal. } \\
\text { (2018) }\end{array}$} & \multirow{2}{*}{$\begin{array}{l}\text { Randomised } \\
\text { control trial } \\
\text { Iran } \\
\text { Multi-centre }\end{array}$} & \multirow{2}{*}{$\begin{array}{l}\mathrm{N}=32 \\
\text { (group 1) } \\
\mathrm{N}=32 \\
\text { (group 2) } \\
\mathrm{N}=32 \\
\text { (group 3) }\end{array}$} & \multirow{2}{*}{$N=32$} & \multirow{2}{*}{$\begin{array}{l}\text { TB, TP and video } \\
\text { (group 1) } \\
\text { TB, TP and } \\
\text { pamphlet } \\
\text { (group 2) } \\
\text { TB, TP and lecture } \\
\text { (group 3) }\end{array}$} & \multirow[t]{2}{*}{$12 \mathrm{y} / 0$} & \multirow{2}{*}{$\begin{array}{l}\text { PI Silness and } \\
\text { Löe }\end{array}$} & $\begin{array}{l}\text { Intervention groups } \\
1,2 \text { and } 3 \text { had SS } \\
\text { improvements in } \mathrm{PI} \text { scores } \\
\text { at } 2 \text { months }\end{array}$ & $<0.001$ \\
\hline & & & & & & & & $\begin{array}{l}\text { No SS differences in } \\
\text { improvements between } \\
\text { group 1, } 2 \text { or } 3\end{array}$ & $<0.001$ \\
\hline \multirow{5}{*}{2} & \multirow{5}{*}{$\begin{array}{l}\text { R. Yazdani } \\
\text { etal. } \\
(2009)\end{array}$} & \multirow{5}{*}{$\begin{array}{l}\text { Randomised } \\
\text { control trial } \\
\text { Iran } \\
\text { Multi-centre }\end{array}$} & \multirow{5}{*}{$\begin{array}{l}\mathrm{N}=135 \\
\text { (group 1) } \\
\mathrm{N}=130 \\
\text { (group 2) }\end{array}$} & \multirow{5}{*}{$N=123$} & \multirow{5}{*}{$\begin{array}{l}\text { OHI via leaflet } \\
\text { (group 1) } \\
\text { OHI via video } \\
\text { (group 2) }\end{array}$} & \multirow{5}{*}{$15 \mathrm{y} / 0$} & \multirow{3}{*}{$\begin{array}{l}\text { Oral } \\
\text { cleanliness: } \\
\text { Modified PI } \\
\text { Silness and Löe }\end{array}$} & $\begin{array}{l}\text { SS improvements in } \mathrm{PI} \text { and } \\
\mathrm{BI} \text { in group } 1 \text { and } 2 \text { when } \\
\text { compared to control }\end{array}$ & $<0.005$ \\
\hline & & & & & & & & $\begin{array}{l}\text { BI reduction in girls from } \\
\text { group } 2 \mathrm{SS}\end{array}$ & $=0.002$ \\
\hline & & & & & & & & $\begin{array}{l}\text { PI reduction in girls from } \\
\text { group } 2 \text { not SS compared } \\
\text { to control }\end{array}$ & $=0.757$ \\
\hline & & & & & & & $\begin{array}{l}\text { Gingival health: } \\
\text { BI from CPI }\end{array}$ & $\begin{array}{l}\text { Group } 1>\text { group } 2 \text { as } \\
\text { preferred OHE material }\end{array}$ & $<0.05$ \\
\hline & & & & & & & $\begin{array}{l}\text { Self- } \\
\text { administered } \\
\text { questionnaire } \\
\text { to assess OHB } \\
\text { change }\end{array}$ & $\begin{array}{l}\text { Self-assessed improvement } \\
\text { in OHB: } \\
\text { Group 1: 'moderate' in } \\
54 \% \text {, and 'very much' in } \\
26 \% \\
\text { Group 2: 'moderate' in } \\
49 \% \text {, and 'very much' in } \\
22 \%\end{array}$ & $>0.05$ \\
\hline \multirow{3}{*}{3} & \multirow{3}{*}{$\begin{array}{l}\text { A. Lees and } \\
\text { W. P. Rock } \\
(2000)\end{array}$} & \multirow{3}{*}{$\begin{array}{l}\text { Randomised } \\
\text { uncontrolled } \\
\text { trial } \\
\text { England } \\
\text { Single-centre }\end{array}$} & \multirow{3}{*}{$\begin{array}{l}\mathrm{N}=21 \\
\text { (group 1) } \\
\mathrm{N}=22 \\
\text { (group 2) } \\
\mathrm{N}=22 \\
\text { (group 3) }\end{array}$} & \multirow{3}{*}{$\begin{array}{l}\text { No } \\
\text { control }\end{array}$} & \multirow{3}{*}{$\begin{array}{l}\text { Written } \mathrm{OHI} \\
\text { (group 1) } \\
\text { Video OHI } \\
\text { (group 2) } \\
\text { OHI by dental } \\
\text { hygienist } \\
\text { (group 3) }\end{array}$} & \multirow{3}{*}{$\begin{array}{l}\text { Not stated } \\
\text { (unable } \\
\text { to contact } \\
\text { author for } \\
\text { clarification) }\end{array}$} & $\begin{array}{l}\text { PI Greene and } \\
\text { Vermillion }\end{array}$ & $\begin{array}{l}\text { PI: } \\
\text { Group } 3>\text { group } 2>\text { group } 1\end{array}$ & $>0.05$ \\
\hline & & & & & & & $\begin{array}{l}\text { GI Silness and } \\
\text { Löe }\end{array}$ & $\begin{array}{l}\text { Gl: } \\
\text { Group } 3>\text { group } 2>\text { group } 1 \\
\text { Not SS }\end{array}$ & $>0.05$ \\
\hline & & & & & & & $\begin{array}{l}\text { DHK } \\
\text { questionnaire }\end{array}$ & $\begin{array}{l}\text { DHK: } \\
\text { Group } 3>\text { group } 2>\text { group } 1 \\
\text { Not SS }\end{array}$ & $>0.05$ \\
\hline
\end{tabular}

$\mathrm{P}=0.757)$. There was a significant reduction in mean sum scores of the gingival bleeding index between intervention groups and control group (at baseline, leaflet group $=4.0$, videotape group $=3.9$ and control group $=3.8$ at baseline $[\mathrm{P}>0.05]$ and at the end 1.6, 1.9 and 3.6, respectively $[\mathrm{P}<0.05]) .{ }^{24}$ Further analysis is required to compare improvements from video education with leaflets for statistical significance.

Yazdani et al. also assessed participant opinion on video and leaflets for oral health education and their perceived knowledge gain post education via video or patient leaflet using a self-administered questionnaire. The results show that $97 \%$ viewed the leaflet as a good educational material with no gender difference and $83 \%$ assessed the video as good material for oral health education $(\mathrm{P}<0.05)$. There was a significant gender difference ( $91 \%$ boys versus $72 \%$ girls, $\mathrm{P}=0.004)$ in the video group. Selfreported improvements in participant oral health behaviours were considered as 'moderate' or 'very much' by $80 \%$ in leaflet group versus $71 \%$ in video group $(\mathrm{P}>0.05)$. A statistically significant higher number of boys than girls reported improvements in the video group $(\mathrm{P}<0.05) .^{24}$

\section{Styles of video-based patient information for oral health promotion}

Methods of video education were different in each study (Table 3). These studies all showed variations in the design and frequency of exposure of the video education to children of different ages in each study. Due to this heterogeneity, no meaningful comparison could be made between the different styles of video education.

\section{Discussion}

This systematic review has yielded only three studies that compared written patient information with video-based media for educating children or parents/carers on oral health. The studies included, although few, did address these aims but the results were varied. However, this review has summarised the current evidence base and will serve to guide future research. It is important to highlight the limitations of this systematic review. Only two databases were searched, only studies in English were considered and unpublished literature was not searched for. The studies included had varying lengths of follow-up, variable participant age groups (one study had an unconfirmed age group), inconsistent use of outcome measurement tools and a lack of data. 
Although the age group was not stated in the paper, it was agreed to include the study by A. Lees and W. P. Rock. after review with CS. It was agreed that as participants had been fitted with a lower fixed appliance in the previous three months and the paper was written in 2000, they were likely adolescents. A. Lees and W. P. Rock was the only study to compare knowledge gain by leaflet and video education using a dental health knowledge questionnaire. ${ }^{26}$ Post-study changes in knowledge for intervention and control groups were statistically insignificant. Positive study attributes include use of individual randomisation of participants, a single, calibrated and blinded examiner and the use of plaque disclosing solution to record plaque indices. However, limitations include a small initial sample size of 65 , participants could not be blinded, the questionnaire or proof of its construct validity was not published and no attempt was made to measure the extent written or video material was used by participants. Unsurprisingly, effectiveness of video education for paediatric dental patients or parents/carers on knowledge of oral health was difficult to fully assess, owing to very limited data and lack of validated outcome tools. Questionnaires are a common and useful tool in research; however, they are susceptible to researcher bias and respondent bias, which may affect their outcome. A solution to this would be to develop a universal, validated questionnaire to assesses oral health knowledge. The authors feel that this questionnaire should include questions regarding oral hygiene regime, knowledge of diet and oral health and understanding of the consequences of poor hygiene and diet. This would standardise studies and allow for comparisons of results.

Change in oral behaviours were assessed in all three studies, but only two showed statistical significance. ${ }^{24,25}$ Ramezaninia et al. showed a decrease in plaque index for participants receiving pamphlet and video education with no statistically significant difference between the groups. ${ }^{25}$ Limitations of this study include an initial sample size of 128 participants, cluster and not individual randomisation of participants, which can reduce study power, plaque disclosing solution was not used for plaque scores and there was no attempt at blinding to reduce observation bias. Yazdani et al. demonstrated statistically significant improvements in plaque and bleeding scores in the leaflet group and the video group when compared to the control. ${ }^{24} \mathrm{~A}$ larger initial sample size of 417 students were recruited based on a power calculation. However, plaque disclosing

Fig. 1 PRISMA flow diagram highlighting the process of study selection. A total of three studies were included in the systematic review



Table 3 Comparison of videos used in each study. Each study used videos of varying designs, lengths and frequencies of exposure

\begin{tabular}{l|l|l|l|l}
\hline Author (year) & $\begin{array}{l}\text { Length of video } \\
\text { (minutes) }\end{array}$ & Exposure to video & Style & $\begin{array}{l}\text { Age of participants } \\
\text { (years) }\end{array}$ \\
\hline $\begin{array}{l}\text { J. Ramezaninia } \\
\text { et al. (2018) }\end{array}$ & 8 & $\begin{array}{l}\text { Week 0 } \\
\text { Week 4 }\end{array}$ & Animated & 12 \\
\hline $\begin{array}{l}\text { R. Yazdani et } \\
\text { al. (2009) }\end{array}$ & 17 & $\begin{array}{l}\text { Week 0 } \\
\text { Week 6 }\end{array}$ & $\begin{array}{l}\text { Vague } \\
\text { Positive messages } \\
\text { about immediate gains } \\
\text { from good oral hygiene }\end{array}$ & 15 \\
\hline $\begin{array}{l}\text { A. Lees and W. } \\
\text { P. Rock (2000) }\end{array}$ & 8 & $\begin{array}{l}\text { Week 0 } \\
\text { Participants took } \\
\text { video home and } \\
\text { kept for the duration } \\
\text { of the study }\end{array}$ & $\begin{array}{l}\text { Animation } \\
\text { Unclear but text states } \\
\text { special effects and } \\
\text { backing music were } \\
\text { used }\end{array}$ & $\begin{array}{l}\text { Not stated } \\
\text { Unable to contact } \\
\text { author for clarification }\end{array}$ \\
\hline
\end{tabular}

solution was not used during examinations. A. Lees and W. P. Rock showed no statistical significance in post-intervention plaque and bleeding scores in the video group, leaflet group and dental hygienist led instruction groups. ${ }^{26}$

The studies assessed the outcome of oral health behaviour using a variety of different plaque and bleeding indices. For example, Yazdani et al. used a modified version of the Silness and Löe PI without disclosing solution but A. Lees and W. P. Rock used Greene and Vermillion PI with disclosing solution. A standardised tool for oral health behaviour outcome measurements would allow for comparison between studies.
Yazdani et al. suggests that leaflets are the preferred educational material when compared to videos. ${ }^{24}$ This study also found video education for 15-year-olds improved oral health behaviour in boys more than girls. ${ }^{24}$ This was not found in the study by Ramezaninia et al., who demonstrated no gender difference in oral health behaviour in 12-year-olds receiving video education. ${ }^{25}$ These are interesting findings; however, these studies are based in Iran, which is culturally different to the UK and compare different age groups. More research based in the $\mathrm{UK}$ is needed before any learning preferences can be drawn. 
In the studies shown, the video education was provided in schools or given to the students to take home and watch. However, we are in a digital age and the internet has become an invaluable source of information. Access to internet in the UK is widely available, with $98 \%$ of all premises having access to efficient (10 Mbit/s and above) fixed-line broadband service. ${ }^{27}$ However, this may not be the case in other countries and accessibility to educational resources needs to be considered. Posting videos on online platforms such as YouTube allows a wider audience to be reached than if these were just played in dental waiting rooms. Research has shown that YouTube is widely used by the public for dental education and can influence public opinion about the dental profession. ${ }^{28}$ However, anyone can upload information to such sites which can include false or misleading oral health information. ${ }^{28}$ It is the authors view that we, as dental professionals, should acknowledge the potential of YouTube and other sites and help to provide accessible, evidence-based educational content. The videos could be subject to patient feedback and regularly updated by dental professionals, to align with the current evidence base. This is more environmentally friendly and avoids the need for printing and distributing new leaflets with each information update.

Unfortunately, due to the heterogeneity between the studies and the low number, it is difficult to draw any conclusions, regarding the effectiveness of video-based education compared to written education for dental education. Yet, we must remember that absence of evidence is not evidence of absence. ${ }^{29}$ Future work should involve pilot studies to create standardised and validated outcome measurement tools to evaluate the oral health educational videos already available, such as the BSPD healthy teeth guide for children videos. This will identify future improvements to video content and optimal video design for different age groups. Given that three-quarters of 5-15-year-olds played games online in $2020,{ }^{30}$ video games are an interesting area of future research for oral health education. A 2012 systematic review concluded that video games have potential to improve health outcomes but that more RCTs were required. None of the included studies in this review addressed oral health education specifically. ${ }^{31}$ A RCT investigated the impact of verbal education versus video games to deliver oral health education on children's oral health knowledge, dietary and oral habits. They found that oral health education using video games can be as effective as one-toone education at three-month telephone review. ${ }^{32}$

\section{Conclusion}

There are currently too few studies with heterogeneity to make conclusions on the impact of written versus video oral health education for parents/carers or children. The authors suggest designing a standardised outcome measurement tool for oral health behaviours and knowledge to evaluate current UK paediatric oral health educational videos and to help guide future developments and research. Although this review is limited, it shows potential for videos to become a tool for mass public education about oral health, especially as we navigate through this 'new normal'.

\section{Ethics declaration}

The authors declare that there are no conflicts of interest.

\section{References}

1. Public Health England. National Dental Epidemiology Programme for England: oral health survey of 5-yearolds 2019. A report on the variations in prevalence and severity of dental decay. 2019. Available at https:// www.gov.uk/government/statistics/oral-health-surveyof-5-year-old-children-2019 (accessed August 2020).

2. Public Health England. National Dental Epidemiology Programme for England: oral health survey of 5-yearolds 2017. A report on the variations in prevalence and severity of dental decay. 2017. Available at https:// www.gov.uk/government/statistics/oral-health-surveyof-5-year-old-children-2017 (accessed August 2020).

3. Locker D, Jokovic A, Stephens M, Kenny D, Tompson $B$, Guyatt $G$. Family impact of child oral and oro-facial conditions. Community Dent Oral Epidemiol 2002; 30: 438-448.

4. Colak H, Dülgergil C T, Dalli M, Hamidi M M. Early childhood caries update: A review of causes, diagnoses, and treatments. J Nat Sci Biol Med 2013; 4: 29-38.

5. Milsom K M, Blinkhorn, Tickle M. The incidence of dental caries in the primary molar teeth of young children receiving National Health Service funded dental care in practices in the North West of England. $\mathrm{Br}$ Dent J 2008; DOI: 10.1038/sj.bdj.2008.582

6. NHS. Hospital admissions for tooth extractions due to tooth decay. 2020. Available at https://digital. nhs.uk/data-and-information/supplementaryinformation/2020/hospital-admissions-for-toothextractions-due-to-tooth-decay (accessed September 2020).

7. Public Health England. Health Matters: Child Dental Health. 2017. Available at https://publichealthmatters blog.gov.uk/2017/06/14/health-matters-child-dentalhealth (accessed July 2020)

8. World Health Organisation. Oral health promotion: an essential element of a health-promoting school. 2003. Available at https://apps.who.int/iris/ handle/10665/70207 (accessed August 2020).

9. Habbu S G, Krishnappa P. Effectiveness of oral health education in children - a systematic review of current evidence (2005-2011). Int Dent J 2015; 65: 57-64.

10. Stein C, Santos N M L, Hilgert J B, Hugo F N. Effectiveness of oral health education on oral hygiene and dental caries in schoolchildren: Systematic review and meta-analysis. Community Dent Oral Epidemiol 2018; 46: 30-37.

11. Kay E J, Locker D. Is dental health education effective? A systematic review of current evidence. Community Dent Oral Epidemiol 1996; 24: 231-235.

12. Tuong W, Larsen $E R$, Armstrong A W. Videos to influence: a systematic review of effectiveness of video-based education in modifying health behaviours J Behav Med 2014; 37: 218-233.

13. Krouse $\mathrm{H} J$. Video modelling to educate patients. J $A d v$ Nurs 2001; 33: 748-757.

14. Yeo K Y, Hashimoto K, Archer T, Kenny K, Pavitt S, Zoltie $T$. Evaluation on the effectiveness of a peer led video on oral hygiene education in young children. J Vis Commun Med 2020; 43: 119-127.

15. Dave M, Seoudi N, Coulthard P. Urgent dental care for patients during the COVID-19 pandemic. Lancet 2020; DOI: 10.1016/S0140-6736(20)30806-0.

16. Hurley $S$, Neligan M. Letters, updates and additional guidance for dental teams. 2020. Available at https:// www.england.nhs.uk/coronavirus/publication/ preparedness-letters-for-dental-care/ (accessed October 2021).

17. British Society of Paediatric Dentistry. How to care for the teeth children aged 7+ with Dr Ranj and Supertooth! 2020. Available at https://www.youtube. $\mathrm{com} /$ watch? $\mathrm{v}=\mathrm{GHS} 27 \mathrm{DHyli0} \& \mathrm{t}=3 \mathrm{~s}$ (accessed July 2020).

18. NHS. Dental standard operating procedure: Transition to recovery. 2020. Available at https://www. england.nhs.uk/coronavirus/wp-content/uploads/ sites/52/2020/06/C1287-Standard-OperatingProcedure_Transition-to-Recovery-A-phasedtransition-for-dental-practices-towards-the-1.pdf (accessed September 2020).

19. Kay E, Vascott D, Hocking A, Nield H, Dorr C, Barrett H. A review of approaches for dental practice teams for promoting oral health. Community Dent Oral Epidemiol 2016; 44: 313-330.

20. Ghaderi F, Adl A, Ranjbar Z. Effect of a leaflet given to parents on knowledge of tooth avulsion. Eur J Paediatr Dent 2013; 14: 13-16.

21. Al-Asfour A, Andersson L. The effect of a leaflet given to parents for first aid measures after tooth avulsion. Dent Traumatol 2008; 24: 515-521.

22. PRISMA. Preferred Reporting Items for Systematic Reviews and Meta-Analyses (PRISMA) Checklist. 2020. Available at http://www.prisma-statement.org (accessed September 2020).

23. NHS. Commissioning Standard for Dental Specialties - Paediatric Dentistry. 2018. Available at https:// www.england.nhs.uk/wp-content/uploads/2018/04/ commissioning-standard-for-dental-specialtiespaediatric-dentristry.pdf (accessed August 2020).

24. Yazdani R, Vehkalahti M M, Nouri M, Murtomaa $H$ School-based education to improve oral cleanliness and gingival health in adolescents in Tehran, Iran. In J Paediatr Dent 2009: 19: 274-281.

25. Ramezaninia J, Naghibi Sistani M M, Ahangari Z, Gholinia H, Jahanian I, Gharekhani S. Comparison of the Effect of Toothbrushing Education Via Video, Lecture and Pamphlet on the Dental Plaque Index of 12-YearOld Children. Children (Basel) 2018; DOI: 10.3390/ children5040050.

26. Lees A, Rock W P. A comparison between written, verbal, and videotape oral hygiene instruction for patients with fixed appliances. J Orthod 2000; 27: 323-328.

27. Ofcom. Connected Nations 2019 UK report. 2019. Available at https://www.ofcom.org.uk/__data/assets/ pdf_file/0023/186413/Connected-Nations-2019-UKfinal.pdf (accessed July 2020).

28. Knösel M, Jung K, Bleckmann A. YouTube, Dentistry, and Dental Education. J Dent Educ 2011; 75: 1558-1568.

29. Ofcom. Online Nation. 2021. Available at https://www. ofcom.org.uk/__data/assets/pdf_file/0013/220414/ online-nation-2021-report.pdf (accessed October 2021).

30. Broadcasters' Audience Researcher Board. The UK Television Landscape Report. Game Console Households. 2020. Available at https://www.barb. co.uk/trendspotting/tracker-games-consoles (accessed September 2020)

31. Primack B A, Carroll M V, McNamara et al. Role of video games in improving health-related outcomes: a systematic review. Am J Prev Med 2012; 42: 630-638.

32. Aljafari A, Gallagher J, Hosey M. Can oral health education be delivered to high-caries-risk children and their parents using a computer game? - A randomised controlled trial. Int J Paediatr Dent 2017; 27: 476-485. 